\section{Dyslipidemia and the risk of incident hypertension in a population of community-dwelling Brazilian elderly: the Bambuí Cohort Study of Aging}

\author{
Dislipidemia e risco de incidência de hipertensão \\ em uma população de idosos brasileiros vivendo \\ em comunidade: Estudo de Coorte de Idosos \\ de Bambuí
}

Marco Polo Dias Freitas 1,2

Antônio Ignácio de Loyola Filho 2,3

Maria Fernanda Lima-Costa 2

\section{Introduction}

1 Hospital Universitário de Brasília, Universidade de Brasília, Brasília, Brasil. 2 Núcleo de Estudos em Saúde Pública e Envelhecimento, Fundação Oswaldo Cruz/Universidade Federal de Minas Gerais, Belo Horizonte, Brasil.

${ }^{3}$ Escola de Enfermagem, Universidade Federal de Minas Gerais, Belo Horizonte, Brasil.

Correspondence M. P. D. Freitas Centro de Medicina do Idoso, Hospital Universitário de Brasília, Universidade de Brasília.

SGAN 605, Brasília, DF 70840-901, Brasil. marcopolo.freitas@gmail.com

\section{Abstract}

This study aimed to examine the prognostic value of lipid parameters for incident hypertension in elderly living in a community. The study included 306 (81\% from total) persons aged $\geq 60$ years who were free of hypertension and of cardiovascular diseases at the baseline survey of the Bambui Cohort Study of Aging. The cumulative incidence of hypertension over three years was $37.3 \%$. The relative risk $(R R)$ of incident hypertension decreased 0.92 for each unit of HDL-cholesterol (95\%CI: 0.86-0.99) independent of several potential confounding factors. Individuals with $H D L$-cholesterol in the top tercile $(\geq 55 \mathrm{mg} / \mathrm{dL}$ ) had a risk of hypertension halve that those in the bottom tercile ( $R R=0.54$; 95\%CI: 0.33-0.90). Other lipid parameters had no significant effect on the outcome. High HDL-cholesterol showed an independent protective effect on subsequent development of hypertension in the elderly.

Dyslipidemias; Hypertension; Aged; Cohort Studies
Arterial hypertension is the principal risk factor for mortality and the second leading cause of disability adjusted life years around the world 1 , 2 . The risk of developing arterial hypertension increases markedly with age 3,4 , and is the most common chronic disease in the elderly, with prevalence of about $60 \%$ in Latin America and the Caribbean 5 , as well as in the town of Bambuí, Minas Gerais State, Brazil 6. Populations in these countries are aging fast 7 and unless effective primary and secondary prevention measures are implemented, this demographic change will bring about a significant increase in the burden of arterial hypertension in this region of the world.

Hypertension and dyslipidemia are widely recognized risk factors for cardiovascular disease 2,8. And yet, the pathophysiology of the association between hypertension and dyslipidemias is still not completely understood 9 . Several mechanisms have been postulated to explain this association. Atherosclerosis - caused in great part by dyslipidemias 9 - leading to structural changes that result in the decreased elasticity of large arteries, is generally viewed as the principal pathophysiologic alteration contributing to the emergence of arterial hypertension in the elderly 10 . By altering vasomotor mechanisms mediated by nitric oxide, dyslipidemias also alter endothelial function 11, which in turn can cause increases in blood pressure. Renal microvascular 
injuries due to dyslipidemias are also postulated to contribute to arterial hypertension 12 . Finally, coincident genetic factors, such as having chromosomal regions related to blood pressure and dyslipidemias in common 13,14 , which predispose for the concomitant occurrence of hypertension and dyslipidemia 15 , and the fact that reductions in blood pressure in hypertensive individuals have been attributed to use of statins 16, suggest shared pathophysiologic mechanisms that need to be better elucidated.

Several studies have examined prospectively whether elevated lipid levels are associated with the subsequent development of hypertension in middle age adults. In most studies, high-density lipoprotein cholesterol (HDL-C) levels show an independent and inverse association with incident hypertension 17,18,19,20,21. Higher levels of triglycerides $18,20,22$, higher total cholesterol (total-C) 19,21, higher non-HDL cholesterol (nonHDL-C) 19,21, and higher levels of low density lipoprotein cholesterol (LDL-C) 17,20 have been found to be associated with an increased risk of hypertension in some studies, but not in all. Nevertheless, the finding of these studies are not entirely comparable, as the participants of the various cohorts differed in terms of age, gender (some studies included only men and others only women), socioeconomic status, ethnicity and the way in which information about hypertension was obtained (self-reported or objective measure), among other relevant aspects.

Moreover, the role of dyslipidemia in predicting hypertension in the elderly has received little attention. To our knowledge, a single previous cohort study on the issue was carried out in the elderly 23 . This study followed 187 initially non-hypertensive elderly; over an eight year follow-up period there were 44 incident cases. HDL-C had a protective effect on the incidence of hypertension (univariate relative risk $-\mathrm{RR}=$ 0.8 per $5 \mathrm{mg} / \mathrm{dL} ; 95 \%$ confidence intervals 95\%CI: 0.42-1.0).

We used data from three years of follow-up of the Bambuí Health and Aging Study to examine whether lipid parameters predict subsequent development of hypertension in old age.

\section{Methods}

\section{Study design and population}

The study was conducted in Bambuí, a town of approximately 15,000 inhabitants, located in the state of Minas Gerais, in Southeastern Brazil. Enrollment and monitoring procedures of the Bambuí Cohort Study of Aging have been described in detail elsewhere 6,24 . Briefly, the baseline cohort population consisted of all residents aged 60 and over on January 1st, 1997 who were identified by means of a complete census in the city. Baseline data collection was performed from February to May, 1997, including standardized interviews, blood tests and blood pressure measurements, among others. Blood pressure measures were repeated in the third wave, which was conducted from March to June, 2000.

All cohort participants who were free of hypertension at baseline (as defined below) and who did not have cardiovascular diseases were eligible for inclusion. Cardiovascular diseases that prompted exclusion were: prior medical diagnosis of myocardial infarction, symptoms of angina pectoris or intermittent claudication 25 , stroke 26 and congestive heart failure. The presence of congestive heart failure was objectively defined by a plasma B-type brain natriuretic peptide (BNP) level > 100pg/mL (MEIA/AxSYM; Abbott, Abbott Park, USA), as recommended by the manufacturer, and QRS interval $\geq 120$ ms on ECG 27 (Hewlett Packard M1700A; Hewlett Packard, Palo Alto, USA).

\section{Definition and measurement of blood pressure}

Three measures of blood pressure were obtained at least two minutes apart. The mean of the second and third measures was used following a standard protocol 28. Blood pressure was measured in the project field study clinic in the early morning, at least 30 minutes after consumption of caffeine and/or use of tobacco and after five minutes of rest. Measurements were taken on the right arm with an appropriate size cuff, using a random zero Mercury sphygmomanometer (Tycos 5097-30; Tycos, Arden, USA) and stethoscope (Littmann Cardiology II; 3M, St. Paul, USA). Systolic and diastolic blood pressures were registered using as a reference the first and the fifth Korotkoff sounds, respectively. The technicians that measured blood pressure were certified after training at a specialized center at the School of Medicine of the Minas Gerais Federal University (Faculdade de Medicina, Universidade Federal de Minas Gerais). The same procedures were used at baseline and during the third year of follow-up.

The use of medications was measured by mean of verifying the packaging and/or the physician's prescription during home visits that were conducted with all participants. Medications were coded according to the Anatomical Therapeutical Chemical Index (ATC/DDD Index) 29 and were considered antihypertensives if they were 
classified in groups ATC: C02 - antihypertensives, C03 - diuretics, C07 - beta-blockers, C08 - calcium channel blockers, and C09 - agents that act on the renin-angiotensin system.

Arterial hypertension was defined in this study as the presence of systolic blood pressure equal or higher than $140 \mathrm{mmHg}$ or diastolic blood pressure equal or higher than $90 \mathrm{mmHg}$ or treatment for hypertension 30 . We considered incident cases those individuals that were free of hypertension at baseline and were found to be hypertensive at the third follow-up visit in 2000 .

\section{Lipids dosages}

Blood specimens for biochemical assays were collected after a recommended 12 hour fast. Serum levels of total-C, HDL-C and triglycerides were determined by enzymatic methods, using standard assay kits (Boehringer Mannhein; Ingelheim am Rhein, Germany). All the measures were performed using an automated analyzer (Eclipse Vitalab, Merck, Schiphol-Rijk, Netherlands) at the study's central laboratory at the René Rachou Research Center of the Oswaldo Cruz Foundation (Centro de Pesquisas René Rachou, Fundação Oswaldo Cruz - CPqRR/Fiocruz). Details are available from other publications 6,24. For the present analysis the following lipid parameters were considered: total-C, HDL-C, non-HDL-C, total-C/HDL-C ratio and triglycerides.

\section{Other measures}

Other baseline measures considered in this study included: age, sex, schooling level (number of complete years of schooling), smoking, physical activities during leisure time, alcohol consumption (weekly frequency in previous 12 months), parental history of cardiovascular diseases (history of myocardial infarction, angina pectoris, hypertension and/or stroke), waist circumference, and fasting blood glucose. Current smokers were those who had smoked at least 100 cigarettes in the lifetime and were still smokers. "No physical activities during leisure time" was defined by the absence of any exercise lasting 20-30 minutes in the previous 90 days. Measures of waist circumference were performed using a flexible inelastic tape measure, with this subject standing.

None of the participants had a history of drug treatment for lowering lipids, and none had used these drugs during the period in which patients were followed. Thus, drugs for lowering cholesterol were not included in the present analysis.

\section{Statistical analyses}

The univariate data analysis was based on Pearson's chi square, Student's t and Mann-Whitney rank sum tests to assess statistical significance of differences between frequencies, means and medians, respectively. The multivariate analyses of predictors of incident hypertension were based on RR and 95\%CI estimated by Poisson regression. Separate multivariate analyses were performed for each lipid parameter; these were categorized in increased units of ten percentiles. The relative risks were incrementally adjusted for age (continuous), sex, and schooling level (model 1), smoking, physical activity and alcohol consumption (model 2), parental history of cardiovascular diseases, waist circumference (continuous), blood glucose in log values (continuous) (model 3) and systolic blood pressure (model 4). A complementary multivariate analysis was implemented based on categorical values of HDL-C to assess its association with incident hypertension. The significance of multiplicative interactions between HDL-C with age or sex on the outcome was examined by using cross-product terms in Poisson regression models. Statistical analyses were conducted using Stata 11.0 statistical software (Stata Corp., College Station, USA). All p-values were 2 -tailed ( $\alpha=0.05$ ).

The Bambuí cohort study was approved by the Ethics Research Committee of Fiocruz. Participants signed an informed consent at enrollment and at each follow-up visit.

\section{Results}

Of 1,742 Bambuí residents aged 60 years and over, 1,494 (85.8\%) had had their blood pressure measured at baseline. Of these, 464 were classified as non-hypertensive. Eighty-five with existing cardiovascular disease were excluded. Of the 379 eligible elderly, 306 had a blood pressure measure recorded at the third year of follow-up and constitute the population base for this study. The other 73 included 55 who had died and 18 who had emigrated or declined to participate.

The baseline characteristics of study participants are shown in Table 1. Mean age was 68.0 (standard deviation $-\mathrm{SD}=6.7$ ) years and women $(54.2 \%)$ outnumbered men. The number of years of formal schooling was very low: $62.4 \%$ had completed less than four years of school. The mean (SD) levels total-C, HDL-C, nonHDL-C, total-C/HDL-C ratio were $230.3 \mathrm{mg} /$ dL (49.4), 50.0mg/dL (13.8), 180.3mg/dL (49.8) and $4.9 \mathrm{mg} / \mathrm{dL}$ (1.7), respectively. The median 
Baseline characteristics of study participants. The Bambuí Cohort Study of Aging

\section{Characteristics}

Total cholesterol in mg/dL [mean (SD)]
HDL cholesterol in mg/dL [mean (SD)]
Non-HDL cholesterol in mg/dL [mean (SD)]
Total cholesterol / HDL cholesterol ratio [mean (SD)]
Triglycerides in mg/dL [median (IQR)]
Age [mean (SD)]
Female sex (\%)
Less than 4 years of schooling (\%)
Current smoking (\%)
Absence of physical activities during leisure times in previous 90 days * (\%)
Alcohol consumption: 1-6 drinks a week in previous 12 months (\%)
Parental history of cardiovascular diseases < 50 years (\%)
Waist circumference in centimeters [mean (SD)]
Blood glucose in mg/dL, [geometric mean (SD)]
Systolic blood pressure in mmHg [mean (SD)]
Diastolic blood pressure in mmHg [mean (SD)]

\% or mean (SD) or median (IQR)

$(\mathrm{N}=306)$

$230.3(49.4)$

$50.0(13.8)$

$180.3(49.8)$

$4.9(1.7)$

$115.5(84-161)$

$68.0(6.7)$

54.2

62.4

18.6

23.1

5.2

23.9

$88.3(10.3)$

$96.0(88-106)$

$120.7(12.1)$

$75.8(8.4)$

IQR: interquartile range; SD: standard deviation.

* Exercises for 20-30 minutes less than 3 times a week;

Table 2

Univariate analysis of the association between baseline characteristics and incident hypertension. The Bambuí Cohort Study of Aging.

\begin{tabular}{|c|c|c|c|}
\hline \multirow[t]{3}{*}{ Baseline characteristics } & \multicolumn{2}{|c|}{ Incident hypertension } & \multirow[t]{3}{*}{ p-value * } \\
\hline & Yes $(n=114)$ & No $(n=192)$ & \\
\hline & $\%$ or mean (SD) & $\%$ or mean (SD) & \\
\hline Total cholesterol in mg/dL [mean (SD)] & $229.7(51.8)$ & $230.7(48.1)$ & 0.861 \\
\hline HDL cholesterol in mg/dL [mean (SD)] & $46.7(12.4)$ & $52.0(14.2)$ & 0.001 \\
\hline Non-HDL cholesterol in mg/dL [mean (SD)] & $182.9(53.2)$ & $178.7(47.7)$ & 0.474 \\
\hline Total cholesterol/HDL cholesterol ratio [mean (SD)] & $5.3(1.9)$ & $4.7(1.5)$ & 0.006 \\
\hline Triglycerides in mg/dL [median (IQR)] & $122.5(86-156)$ & $110(82-161)$ & 0.380 \\
\hline Age [mean (SD)] & $67.7(6.6)$ & $68.3(6.8)$ & 0.516 \\
\hline Female sex (\%) & 54.2 & 57.0 & 0.454 \\
\hline Less than 4 years of schooling (\%) & 62.0 & 61.4 & 0.778 \\
\hline Current smoking (\%) & 21.0 & 17.2 & 0.401 \\
\hline Absence of physical activities during leisure times in previous 90 days (\%) & 86.0 & 74.0 & 0.014 \\
\hline Alcohol consumption: 1-6 drinks a week in previous 12 months (\%) & 6.1 & 4.7 & 0.581 \\
\hline Parental history of cardiovascular diseases $<50$ years $(\%)$ & 21.1 & 15.6 & 0.229 \\
\hline Waist circumference in centimeters [mean (SD)] & $89.8(11.0)$ & $87.4(9.9)$ & 0.051 \\
\hline Blood glucose in mg/dL [median (IQR)] & $98(90-107)$ & $95(87-105)$ & 0.167 \\
\hline Systolic blood pressure in mmHg [mean (SD)] & $124.4(10.9)$ & $118.5(12.3)$ & $<0.001$ \\
\hline Diastolic blood pressure in mmHg [mean (SD)] & $78.2(8.2)$ & $74.3(8.3)$ & $<0.001$ \\
\hline
\end{tabular}

IQR: interquartile range; SD: standard deviation.

* p-value: Pearson's chi square, Student's t and Mann-Whitney rank sum tests for differences between frequencies, means and medians, respectively. 
triglyceride level was $115.5 \mathrm{mg} / \mathrm{dL}$ (interquartile range $-\mathrm{IQR}=84-161$ ).

The cumulative incidence of hypertension over three years was $37.3 \%$. Results of the univariate analysis of factors associated with the development of hypertension are presented in Table 2 . Statistically significant $(\mathrm{p}<0.05)$ associations with incident hypertension were observed for total-C/HDL-C ratio, HDL-C, absence of physical activity during leisure time, systolic blood pressure, and diastolic blood pressure. Waist circumference was at the borderline of the statistical significance. Other variables did not reach statistical significance in this analysis.

After adjustments for potential confounding variables (Table 3 ), there was a significant association between decreased HDL-C level and incident hypertension (fully adjusted $R R=0.92$; 95\%CI: 0.86-0.99). A significant relative risk was also observed for Total-C/HDL ratio in the analysis adjusted by socio-demographic variables, but this association disappeared after adjustments for lifestyle and other relevant characteristics. Total-C, non-HDL-C and triglycerides were not found to be associated with the risk of hypertension in any of the multivariate models.

A HDL-C level in the top tercile $(55 \mathrm{mg} / \mathrm{dL}$ and over) in comparison with the bottom tercile showed an independent and protective effect for incident hypertension (fully adjusted $R R=0.54$; 95\%CI: 0.33-0.90) (Table 4). No significant effect modifiers between age and sex on the association between HDL-C and incident hypertension (p-value for interaction $=0.249$ for age and 0.738 for sex) was found.

\section{Discussion}

This study provides epidemiological evidence of a protective effect of HDL-C level on the risk of hypertension in an elderly population initially free of cardiovascular diseases. This association persisted after adjustments for several potential confounding variables, including baseline systolic blood pressure level, and suggests a graded effect. Low HDL-C appears to precede the development of hypertension by at least three years.

Population-based studies of the incidence of arterial hypertension in Brazil are rare. To our knowledge there is only one population-based cohort study of middle-aged individuals on this issue. This study was conducted in the city of Porto Alegre, Rio Grande do Sul State, South of Brazil 31. Among 589 normotensive individuals (mean age $=39$ years), 127 (21.6\%) developed arterial hypertension after a mean follow-up of 5.6 years. After adjustments for relevant characteristics, age and waist/height ratio were the only factors that remained significantly associated with the incidence of arterial hypertension. The present study was conducted in an older community-based cohort (mean age $=68$ years). The 3-year incidence of hypertension was higher (37.3\%) than that of the above mentioned study, but similar to that observed among elderly participants of the Framingham Study cohort, over the course of four years of follow-up 32 .

HDL-C levels are importantly affected by age, and a protective effect of increased HDL-C level on incident hypertension in the elderly is plausible. Longitudinal studies have shown that there is a decline in serum HDL-C levels with increasing age 33,34 , while in cross-sectional stud-

Multivariate-adjusted relative risks (RR) and $95 \%$ confidence intervals $(95 \% \mathrm{Cl})$ for ten percentile unit increments in each lipid parameter. The Bambuí Cohort Study of Aging.

\begin{tabular}{lcccc}
\hline Baseline lipid parameter & Model 1 & Model 2 & Model 3 & Model 4 \\
& RR (95\%Cl) & RR (95\%Cl) & RR (95\%Cl) & RR (95\%Cl) \\
\hline Total cholesterol & $0.98(0.91-1.04)$ & $0.98(0.91-1.04)$ & $0.97(0.91-1.04)$ & $0.97(0.91-1.04)$ \\
HDL cholesterol & $0.92(0.86-0.98) *$ & $0.92(0.86-0.98)$ * & $0.93(0.87-0.99) *$ & $0.92(0.86-0.99) *$ \\
Non-HDL cholesterol & $1.00(0.86-0.98)$ & $1.00(0.94-1.07)$ & $1.00(0.93-1.07)$ & $0.99(0.93-1.06)$ \\
Total cholesterol/HDL cholesterol ratio & $1.06(1.00-1.13) *$ & $1.06(0.99-1.12)$ & $1.04(0.97-1.12)$ & $1.05(0.98-1.12)$ \\
Triglycerides & $1.02(0.95-1.09)$ & $1.02(0.96-1.09)$ & $1.01(0.94-1.08)$ & $1.01(0.94-1.08)$ \\
\hline
\end{tabular}

Model 1: adjusted for age, sex, and schooling; Model 2: adjusted for the variables in Model 1 and smoking, physical activity, and alcohol consumption; Model 3: adjusted for the variables in Model 2 and parental history of cardiovascular diseases, waist circumference, and blood glucose; Model 4: adjusted for the variables in Model 3 and systolic blood pressure.

* p-value $<0.05$ (Wald's test). 
Multivariate-adjusted relative risks (RR) and $95 \%$ confidence intervals $(95 \% \mathrm{Cl})$ for incident hypertension, by baseline HDL cholesterol level. The Bambuí Cohort Study of Aging.

\begin{tabular}{lcc}
\hline Baseline HDL cholesterol in $\mathrm{mg} / \mathrm{dL}$ & $\mathrm{RR}(\mathbf{9 5 \% \mathrm { Cl } ) *}$ & $\mathrm{p}$-value ** \\
\hline$<43$ (bottom tertile) & 1.00 & \\
$44-54$ & $0.75(0.49-1.15)$ & 0.191 \\
$\geq 55$ (top tertile) & $0.54(0.33-0.90)$ & 0.018 \\
\hline
\end{tabular}

* Relative risk and 95\% confidence intervals estimated by Poisson regression and adjusted for age, sex, schooling, current smoking, physical activities, alcohol consumption, parental history of cardiovascular diseases, waist circumference, blood glucose and systolic blood pressure;

** p-value: Wald's test. itself can intensify arterial stiffening and compromise endothelium-dependent vasodilatation 44 . In one of the analyses of the Framingham Heart Study, Franklin et al. 45 showed that the continuous increase in systolic blood pressure after 60 years of age has a strong relationship with the increasing in large artery stiffness and that even a high normal systolic blood pressure may intensify the arterial rigidity, resulting in a vicious cycle that culminates in arterial hypertension. It seems that is atherosclerosis, provoked in great part by the dyslipidemia ${ }^{9}$, promotes structural and functional alterations that result in reduced elasticity of the large arteries: principal pathophysiologic alteration of the emergence of arterial hypertension in the elderly 10 .

Strengths of this study include the community-based sample, the standardized and systematic measures of parameters at baseline, standardized blood pressure measures at baseline and at follow-up, and minimal loss of participants to follow-up. This allowed a meaningful estimate of a three-year accumulative risk of hypertension. This study has some limitations. There were only 114 incident cases of hypertension among cohort members. This potentially limits the statistical power to detect small effects in our analysis. Because blood pressure measurements were performed in a single day, our results are subject to effects of regression to the mean, which would tend to underestimate the strength of the associations found. Residual confounding is a possibility. Nevertheless, we were able to adjust relative risks for socio-demographic variables and traditional cardiovascular risk factors. Observer bias is unlikely because blood pressure measures and lab tests were performed independently, and without knowledge of the respective results.

Lower serum levels of HDL-C went unrecognized as a predictor of subsequent hypertension for a long time. Only recently has evidence emerged from cohort studies indicating an inverse association between HDL-C and incident hypertension in middle-aged 17,18,19,20,21 and older 23 persons in North America and/or Western Europe. Our study extends this observation to a Brazilian elderly population. The consistency of this association suggests that HDL-C measurements may be useful to identify persons at increased risk of hypertension in primary care settings for prevention. 


\section{Resumo}

O objetivo do estudo foi examinar o valor prognóstico de parâmetros lipídicos para a incidência de hipertensão arterial em idosos vivendo na comunidade. A pesquisa incluiu 306 (81\% do total) pessoas com idade $\geq 60$ anos que estavam livres de hipertensão e de doenças cardiovasculares na linha de base do Estudo de Coorte de Idosos de Bambuí. A incidência acumulada em três anos da hipertensão arterial foi de 37.3\%. O risco relativo (RR) para a incidência da hipertensão diminuiu 0,92 para cada unidade de colesterol HDL (IC95\%: 0,86-0,99), independente de vários potenciais fatores de confusão. Indivíduos com colesterol HDL no tercil superior ( $\geq 55 \mathrm{mg} / \mathrm{dL}$ ) apresentaram metade do risco de hipertensão que aqueles no tercil inferior ( $R R=$ 0,54; IC95\%: 0,33-0,90). Os outros parâmetros lipídicos não apresentaram efeitos estatisticamente significantes sobre o evento. Valores mais altos de colesterol HDL apresentaram efeito protetor para o desenvolvimento da hipertensão em idosos.

Dislipidemias; Hipertensão; Idoso; Estudos de Coortes

\section{Contributors}

M. P. D. Freitas contributed to the conception and design, analysis and interpretation of the data, drafting the article, and final approval of the version to be published. A. I. Loyola Filho collaborated on the analysis and interpretation of the data; revision of the article; and final approval of the version to be published. M. F. Lima-Costa contributed to the conception and design, acquisition of data, analysis and interpretation of the data, revision of the article, and final approval of the version to be published.

\section{Conflicting interests}

None declared.

\section{Acknowledgments}

This study was sponsored by FINEP, CNPq and FAPEMIG.

\section{References}

1. Lopez AD, Mathers CD, Ezzati M, Jamison DT, Murray CJ. Global and regional burden of disease and risk factors, 2001: systematic analysis of population health data. Lancet 2006; 367:1747-57.

2. Lawes CM, Vander Hoorn S, Rodgers A; International Society of Hypertension. Global burden of blood-pressure-related disease, 2001. Lancet 2008; 371:1513-8.

3. Dannenberg AL, Garrison RJ, Kannel WB. Incidence of hypertension in the Framingham Study. Am J Public Health 1988; 78:676-9.

4. Vasan RS, Beiser A, Seshadri S, Larson MG, Kannel WB, D'Agostino RB, et al. Residual lifetime risk for developing hypertension in middle-aged women and men: The Framingham Heart Study. JAMA 2002; 287:1003-10.

5. Kearney PM, Whelton M, Reynolds K, Muntner P, Whelton PK, He J. Global burden of hypertension: analysis of worldwide data. Lancet 2005; 365 : 217-23.
6. Lima-Costa MF, Firmo JOA, Uchôa E. The Bambuí Cohort Study of Aging: methodology and health profile of participants at baseline. Cad Saúde Pública 2011; 27 Suppl 3:S327-35.

7. Palloni A, Pinto-Aguirre G, Pelaez M. Demographic and health conditions of ageing in Latin America and the Caribbean. Int J Epidemiol 2002; 31:762-71.

8. Emerging Risk Factors Collaboration; Di Angelantonio E, Sarwar N, Perry P, Kaptoge S, Ray KK, et al. Major lipids, apolipoproteins, and risk of vascular disease. JAMA 2009; 302:1993-2000.

9. Oparil S, Zaman MA, Calhoun DA. Pathogenesis of hypertension. Ann Intern Med 2003; 139:761-76.

10. Chobanian AV. Clinical practice. Isolated systolic hypertension in the elderly. N Engl J Med 2007; 357:789-96.

11. Nofer JR, Kehrel B, Fobker M, Levkau B, Assmann G, von Eckardstein A. HDL and arteriosclerosis: beyond reverse cholesterol transport. Atherosclerosis 2002; 161:1-16. 
12. Schaeffner ES, Kurth T, Curhan GC, Glynn RJ, Rexrode KM, Baigent C, et al. Cholesterol and the risk of renal dysfunction in apparently healthy men. J Am Soc Nephrol 2003; 14:2084-91.

13. Hunt SC, Ellison RC, Atwood LD, Pankow JS, Province MA, Leppert MF. Genome scans for blood pressure and hypertension: the National Heart, Lung, and Blood Institute Family Heart Study. Hypertension 2002; 40:1-6.

14. Shi G, Gu CC, Kraja AT, Arnett DK, Myers RH, Pankow JS, et al. Genetic effect on blood pressure is modulated by age: the Hypertension Genetic Epidemiology Network Study. Hypertension 2009; 53:35-41.

15. National Cholesterol Education Program (NCEP) Expert Panel on Detection, Evaluation, and Treatment of High Blood Cholesterol in Adults (Adult Treatment Panel III). Third Report of the National CholesterolEducation Program (NCEP) Expert Panel on Detection, Evaluation, and Treatment of High Blood Cholesterol in Adults (Adult Treatment Panel III) final report. Circulation 2002; 106:3143-421.

16. Koh KK, Quon MJ, Waclawiw MA. Are statins effective for simultaneously treating dyslipidemias and hypertension? Atherosclerosis 2008; 196:1-8.

17. de Simone G, Devereux RB, Chinali M, Roman MJ, Best LG, Welty TK, et al. Risk factors for arterial hypertension in adults with initial optimal blood pressure: the Strong Heart Study. Hypertension 2006; 47:162-7.

18. Haffner SM, Ferrannini E, Hazuda HP, Stern MP. Clustering of cardiovascular risk factors in confirmed prehypertensive individuals. Hypertension 1992; 20:38-45.

19. Halperin RO, Sesso HD, Ma J, Buring JE, Stampfer MJ, Gaziano JM. Dyslipidemia and the risk of incident hypertension in men. Hypertension 2006; 47:45-50.

20. Laaksonen DE, Niskanen L, Nyyssönen K, Lakka TA, Laukkanen JA, Salonen JT. Dyslipidaemia as a predictor of hypertension in middle-aged men. Eur Heart J 2008; 29:2561-8.

21. Sesso HD, Buring JE, Chown MJ, Ridker PM, Gaziano JM. A prospective study of plasma lipid levels and hypertension in women. Arch Intern Med 2005; 165:2420-7.

22. Dyer AR, Liu K, Walsh M, Kiefe C, Jacobs Jr. DR, Bild DE. Ten-year incidence of elevated blood pressure and its predictors: the CARDIA study. Coronary Artery Risk Development in (Young) Adults. J Hum Hypertens 1999; 13:13-21.

23. Wildman RP, Sutton-Tyrrell K, Newman AB, Bostom A, Brockwell S, Kuller LH. Lipoprotein levels are associated with incident hypertension in older adults. J Am Geriatr Soc 2004; 52:916-21.

24. Lima-Costa MF, Firmo JOA, Uchôa E. Cohort profile: the Bambuí (Brazil) Cohort Study of Aging. Int J Epidemiol 2010; [Epub ahead of print].

25. Rose GA. The diagnosis of ischaemic heart pain and intermittent claudication in field surveys. Bull World Health Organ 1962; 27:645-58.

26. Plan and operation of the Third National Health and Nutrition Examination Survey, 1988-94. Series 1: programs and collection procedures. Vital Health Stat 1 1994; (32):1-407.
27. Murkofsky RL, Dangas G, Diamond JA, Mehta D, Schaffer A, Ambrose JA. A prolonged QRS duration on surface electrocardiogram is a specific indicator of left ventricular dysfunction. J Am Coll Cardiol 1998; 32:476-82.

28. Perloff D, Grim C, Flack J, Frohlich ED, Hill M, McDonald M, et al. Human blood pressure determination by sphygmomanometry. Circulation 1993; 88(5 Pt 1):2460-70

29. WHO Collaborating Centre for Drug Statistics Methodology. Guidelines for ATC classification and DDD assignment 2010. 13 th Ed. Oslo: World Health Organization; 2009.

30. Chobanian AV, Bakris GL, Black HR, Cushman WC, Green LA, Izzo Jr. JL, et al. The Seventh Report of the Joint National Committee on Prevention, Detection, Evaluation, and Treatment of High Blood Pressure: the JNC 7 report. JAMA 2003; 289:2560-72.

31. Moreira LB, Fuchs SC, Wiehe M, Gus M, Moraes RS, Fuchs FD. Incidence of hypertension in Porto Alegre, Brazil: a population-based study. J Hum Hypertens 2008; 22:48-50.

32. Vasan RS, Larson MG, Leip EP, Kannel WB, Levy D. Assessment of frequency of progression to hypertension in non-hypertensive participants in the Framingham Heart Study: a cohort study. Lancet 2001; 358:1682-6.

33. Ferrara A, Elizabeth BC, Shan J. Total, LDL, and HDL cholesterol decrease with age in older men and women: the Rancho Bernardo Study 19841994. Circulation 1997; 96:37-43.

34. Wilson PW, Anderson KM, Harris T, Kannel WB, Castelli WP. Determinants of change in total cholesterol and HDL-C with age: the Framingham Study. J Gerontol 1994; 49:M252-7.

35. Walter M. Interrelationships among HDL metabolism, aging, and atherosclerosis. Arterioscler Thromb Vasc Biol 2009; 29:1244-50.

36. Prospective Studies Collaboration; Lewington S, Whitlock G, Clarke R, Sherliker P, Emberson J, Halsey J, et al. Blood cholesterol and vascular mortality by age, sex, and blood pressure: a meta-analysis of individual data from 61 prospective studies with 55,000 vascular deaths. Lancet 2007; 370:1829-39.

37. Terasaka N, Yu S, Yvan-Charvet L, Wang N, Mzhavia $\mathrm{N}$, Langlois R, et al. ABCG1 and HDL protect against endothelial dysfunction in mice fed a highcholesterol diet. J Clin Invest 2008; 118:3701-13.

38. Kuvin JT, Rämet ME, Patel AR, Pandian NG, Mendelsohn ME, Karas RH. A novel mechanism for the beneficial vascular effects of high-density lipoprotein cholesterol: enhanced vasorelaxation and increased endothelial nitric oxide synthase expression. Am Heart J 2002; 144:165-72.

39. Naito T, Sawabe M, Arai T, Chida K, Hamamatsu A, Harada $\mathrm{K}$, et al. Dyslipidemia is a major determinant of systemic atherosclerosis in the elderly: An autopsy study. Geriatr Gerontol Int 2007; 7:229-37.

40. Amarenco P, Labreuche J, Touboul PJ. High-density lipoprotein-cholesterol and risk of stroke and carotid atherosclerosis: a systematic review. Atherosclerosis 2008; 196:489-96. 
41. Havlik RJ, Brock D, Lohman K, Haskell W, Snell P, O'Toole M, et al. High-density lipoprotein cholesterol and vascular stiffness at baseline in the activity counseling trial. Am J Cardiol 2001; 87:104-7.

42. Yeboah J, Burke GL, Crouse JR, Herrington DM Relationship between brachial flow-mediated dilation and carotid intima-media thickness in an elderly cohort: the Cardiovascular Health Study. Atherosclerosis 2008; 197:840-5.

43. Yambe M, Tomiyama H, Yamada J, Koji Y, Motobe $\mathrm{K}$, Shiina K, et al. Arterial stiffness and progression to hypertension in Japanese male subjects with high normal blood pressure. J Hypertens 2007; 25:87-93.
44. Lind L. Systolic and diastolic hypertension impair endothelial vasodilatory function in different types of vessels in the elderly: the Prospective Investigation of the Vasculature in Uppsala Seniors (PIVUS) study. J Hypertens 2006; 24:1319-27.

45. Franklin SS, Gustin 4th W, Wong ND, Larson MG, Weber MA, Kannel WB, et al. Hemodynamic patterns of age-related changes in blood pressure: the Framingham Heart Study. Circulation 1997; 96:308-15.

Submitted on 24/Aug/2010

Final version resubmitted on 22/Feb/2011

Approved on 28/Feb/2011 